\title{
DA EDUCAÇÃO RURAL A EDUCAÇÃO DO CAMPO: UMA REFLEXÃO NECESSÁRIA
}

Rosemeri Scalabrin ${ }^{1}$

\begin{abstract}
RESUMO
Este artigo discute sobre a educação do campo, no sentido de localizá-la historicamente e identificar as concepções que marcaram cada época, bem como as práticas pedagógicas desenvolvidas no Campus Rural de Marabá no período de 2010-2016. Para isso, realizou-se a pesquisa bibliográfica e documental, composta pelo estudo do Projeto político pedagógico e relatórios tanto da formação continuada quanto da avaliação institucional e docente. O resultado da pesquisa aponta, de um lado, avanços construídos coletivamente no âmbito da educação interdisciplinar e integrada e, de outro, lacunas vivenciadas no decorrer deste percurso, bem como aponta elementos necessários ao resgate da materialidade de origem da proposta pedagógica institucional que se sofreram mudanças fruto do processo de institucionalização da educação do campo.
\end{abstract}

Palavras chaves: Educação do campo, currículo, práticas pedagógicas.

\begin{abstract}
This article discusses the field education, in the sense of locating it historically and identify the conceptions that marked each epoch, as well as the pedagogical practices developed in the Rural Campus of Marabá - IFPA, in the period of 2010-2016. For this, the bibliographical and documentary research was carried out, composed by the study of the Political Pedagogical Project and reports of the continuous formation as well as the institutional and teaching evaluation. The research results point, on the one hand, to advances built collectively in the scope of interdisciplinary and integrated education and, on the other, gaps experienced during this course, as well as points necessary elements to the rescue of the materiality of origin of the institutional pedagogical proposal that were suffered changes resulting from the process of institutionalization of rural education.
\end{abstract}

Key words: Field education, curriculum, pedagogical practices.

\section{UM POUCO DE HISTÓRIA: DA EDUCAÇÃO TRADICIONAL À EDUCAÇÃO DO CAMPO}

A história da educação brasileira tem sido marcada pela influência externa cujos modelos e propostas pedagógicas tiveram como base inicial o conservadorismo jesuítico de cunho religioso e, posteriormente, a educação tradicional e tecnicista, marcada pela transmissão de conteúdos que interessavam aos donos do poder econômico e político do país em cada época.

\footnotetext{
${ }^{1}$ Licenciada em Pedagogia pela Universidade Federal do Pará (1998), Mestre e Doutora em Educação pela Universidade Federal do Rio Grande do Norte (2011) e Pós-doutora em Estudos Curriculares pela Universidade do Minho-Portugal; Professora da educação do campo do Instituto Federal de Educação, Ciência e Tecnologia do Pará com atuação no Campus Rural de Marabá (CRMB); e membro do Comitê Científico do IFPA (IFPA) e do Conselho Editorial da Editora On-Line Portugal. Tem experiência na área da Educação em temáticas como: Educação do Campo, Ensino, Práticas docentes e Currículo. rose.scalabrin@ifpa.eu.br.
} 
O pensamento pedagógico do período colonial à República Nova, as pseudos políticas de educação destinadas para o campo estiveram vinculadas aos padrões de desenvolvimento socioeconômico do meio rural. A educação no meio rural era destinada para uma minoria privilegiada. Discutindo sobre as influências no pensamento didático brasileiro, Mendes (2006, p 04) destaca que:

O pensamento didático brasileiro teve sua construção desde as primeiras inserções da educação jesuítica entre nós, ampliando-se no período imperial. Sofreu influências da escolástica e do renascimento europeu, até configurar-se mais formalmente na primeira metade do século XX. Mas só a partir da década de 1960 até os dias atuais, configurou-se mais fortemente por um modelo didático caracteristicamente brasileiro.

Para esse autor, o modelo da escola tradicional apresenta dois aspectos que o caracteriza: a ordem externa e a disciplina normativa. Neste sentido, a escola se pauta em poucas estruturas organizativas, as quais são do tipo linear, verticais e normativas; na autoridade do professor que desenvolve conteúdos fragmentados por concebê-los de formas isoladas, centrado nos livros didáticos e na avaliação como controle da aprendizagem; na gestão burocrata e autoritária preocupada unicamente com o controle da aplicação dos programas de ensino.

Esse modelo de escola se inspirou na estrutura de funcionamento das organizações militares e das fábricas criadas a partir da Revolução Industrial cujo desenvolvimento se deu no decorrer do século XIX, porém até a atualidade subsiste nos sistemas escolares, sobretudo, nas práticas docentes (MENDES, 2006).

Nas primeiras décadas da República, havia um padrão de desenvolvimento agrícola rudimentar, e o discurso oficial não considerava necessária a formação escolar para os trabalhadores e trabalhadoras do campo, pois defendia-se que a força física era o suficiente.

As escolas no campo surgiram tardiamente e não institucionalizadas pelo Estado e com forte interferência do modelo econômico capitalista. Segundo Soares (2001, p 07):

A educação rural não foi sequer mencionada nos textos constitucionais de 1824 e 1981, evidenciando-se, de um lado, o descaso dos dirigentes com a educação do campo e, do outro, os resquícios de matrizes culturais vinculadas a uma economia agrária apoiada no latifúndio e no trabalho escravo.

Em contraposição ao modelo de educação tradicional, emergiu, a partir de 1882, as ideias da Escola Nova introduzidas no Brasil por Rui Barbosa (1849-1923) a partir de críticas ao saber pronto e acabado centrado na autoridade do professor e se referencia na visão de escola aberta, descentralizada e crítica da sociedade. O modelo da Escola Nova no Brasil teve 
seu ponto alto em 1932, com a publicação do Manifesto dos Pioneiros da Educação Nova, liderado pelos educadores Fernando de Azevedo, Lourenço Filho e Anísio Teixeira.

A Escola Nova colocou o aluno no centro do processo de ensino-aprendizagem e baseou a atividade escolar no estudo e na pesquisa para a formação do pensamento autônomo e propôs o desenvolvimento de um conjunto de recursos capazes de articular os conteúdos às experiências dos estudantes, de desenvolver a avaliação de natureza qualitativa a fim de valorizar a participação ativa dos estudantes e o crescimento subjetivo no processo de construção da aprendizagem.

Nesta perspectiva, a disciplina deixa de ser priorizada e a convivência coletiva passa a ser o elemento decisivo no estímulo à participação, à autogestão e à auto responsabilidade, tanto por parte dos professores e alunos quanto da comunidade envolvida. Observa-se que embora a Escola Nova represente um marco inovador da educação, este movimento enfrentou críticas de outro movimento denominado de a oposição ao escolanovismo, desenvolvido por educadores em São Paulo, entre 1931, sob a liderança de Sud Mennucci.

A principal crítica se deu pelo fato do Modelo de Escola Nova se basear em sociedades externas e industrializadas (europeia e americana), e, por isso, representava uma cópia de um modelo de escola que não representava a vocação do Brasil que era a agricultura. A não adequação refere-se aos métodos, metodologias e propostas pedagógicas apresentadas, pelo fato de se restringirem ao atendimento da sociedade urbana que trabalhava na indústria, sendo que o Brasil da época possuía a produção agrícola como atividade principal.

A tentativa de replicar este modelo de escola no Brasil ocasionava uma "macaqueação", exatamente por desconsiderar a vocação agrícola brasileira e a ausência de iniciativas para combater o preconceito existente em relação ao trabalho agrícola, o qual trazia o peso da escravidão, ou seja, o trabalho no campo era mal visto por conta do trabalho escravo e os agricultores eram tidos como atrasados. Além disso, este autor destacava que o tipo de formação desenvolvida na escola brasileira era nocivo a população do meio rural, sendo considerada como um veneno por desvalorizar e discriminar o homem do campo, por ver o povo do sertão (meio rural) como sinônimo de atraso.

Assim, o distanciamento da escola em relação a vida no campo tornava a escola desnecessária, motivo pelo qual era melhor que essa escola deixasse de existir, pois o tipo de formação oferecida só servia para tirar energia do homem do campo, menosprezar a vida no campo, devido o currículo inadequado, porque se pautava na sociedade industrializada, portanto urbana. 
Nesse seguimento, o movimento de oposição ao escolanovismo propunha uma escola que desenvolvesse a proposta pedagógica a partir da realidade brasileira que era o rural, em que o principal papel da escola deveria ser eliminar o estigma e o preconceito existente; trazer elementos novos capaz de valorizar o campo; possibilitar que a escola do meio rural se adaptasse à rotina do campo passando a considerar os períodos de colheitas; inserir no currículo escolar noções de agronomia e educação sanitária.

E, para isso, era necessário um calendário escolar que respeitasse o processo de produção e um currículo que contribuísse para que o homem do campo produzisse da melhor maneira possível. De tal modo, que se fazia fundamental investir na formação de professores, a qual também deveria ser diferenciada, portanto composta por noção de agronomia, educação sanitária e de valorização da vida no campo. E os professores deveriam se tornar agente de desenvolvimento do campo e abandonar a característica assumida pelas normalistas ${ }^{2}$.

Esse movimento também denominado de ruralismo pedagógico propôs a criação de escolas normais no campo com conteúdos diferenciados e adequados à questão agrícola brasileira, a partir dos seguintes princípios: a valorização de atividades escolares em espaços teóricos e em espaços do campo; valorização do campo; combate a desvalorização do campo; desenvolvimento do campo.

Discutindo sobre o referido movimento, Calazans (1981, p. 03) destaca que:

\begin{abstract}
Na década de 40 ainda estavam em vigência em algumas regiões do país as ideias do "ruralismo pedagógico" [...], como uma tentativa de resposta à "questão social", provocada pela inchação das cidades e incapacidade de absorção de toda a mão-deobra disponível pelo mercado de trabalho urbano. A essa ameaça permanente, sentida pelos grupos dominantes, políticos e educadores tentavam responder com uma educação que levasse o homem do campo a compreender o "sentido rural da civilização brasileira" e a reforçar os seus valores, a fim de fixá-lo à terra, o que acarretaria a necessidade de adaptar programas e currículos ao meio físico e à cultura rural.
\end{abstract}

A proposta de desenvolvimento de escolas normais no campo com currículo diferenciado e adequado a vocação agrícola brasileira passou a ser desenvolvido sob a coordenação da Direção de Ensino de São Paulo, em 1931, porém o tempo restrito de permanência na gestão do ensino impossibilitou a sua materialização, devido a instalação do governo brasileiro de Getulio Vargas (1930-1945) centralizador e interventor, o qual tirou a autonomia das escolas e dos estados.

\footnotetext{
2 As normalistas eram professores que atuavam no "sertão" (nas escolas do meio rural brasileiro), porém sem formação adequada discriminavam o homem do campo e a sua forma de vida, portanto a atuação docente funcionavam como estimuladora do êxodo rural, na medida em que fortalecia a ideia de inferiorização da população do campo em relação a da cidade e colocava a cidade como o bom lugar de morar.
} 
Nos períodos pós-guerras, com o paradigma modernizador, surgiu a ideia da adequação da escola rural às novas exigências do desenvolvimento econômico, que se deu sob forte influência escolanovista ${ }^{3}$. Como consequência disto, os anos de 1930 e 1950 também foram carentes de políticas educativas inovadoras para o campo. Deste modo, a política educativa se restringiu ao desenvolvimento de programas educativos destinados às bases populares na maioria dos estados brasileiros e de campanhas de alfabetização de caráter assistencialista destinadas a população do campo, as quais continuavam a ser vista como pessoas incultas, atrasadas e desajustadas.

Nos anos de 1960, emergiram os movimentos de educação popular com adoção de novas iniciativas no âmbito da educação popular, tais como: as escolas radiofônicas vinculadas ao Movimento de Educação de Base (MEB), que apresentavam como fundamentação teórica a perspectiva da Pedagogia Libertadora, proposta por Paulo Freire.

Com o golpe militar, em 1964, ocorreu a interrupção da maioria dos programas de alfabetização e educação popular de jovens e adultos da cidade e do campo, configurando um retrocesso da política educacional.

Nos anos de 1970, chegou ao Brasil a proposta pedagógica da Escola Família Agrícola (EFA) pautada nos princípios da Pedagogia da Alternância ${ }^{4}$, a qual teve origem na Itália, em 1960. No Brasil, a EFA foi desenvolvida inicialmente no Estado do Espírito Santo pelo educador italiano Paolo Nozella ${ }^{5}$ através do Movimento de Educação Promocional do (MEPES) com o apoio da Igreja e da sociedade italiana, sem qualquer apoio ou interferência do governo militar.

As experiências das EFAS se fundamentaram na prática em que os jovens passavam duas semanas recebendo conhecimentos gerais e técnicos voltados para a realidade agrícola regional e duas semanas nas propriedades rurais, aplicando os conhecimentos recebidos no tempo presencial (REIS, 2006). A atuação das Escolas Famílias Agrícolas (EFAs) representa

\footnotetext{
${ }^{3}$ No Brasil, a Escola Nova buscava a modernização, a democratização, a industrialização e urbanização da sociedade. Os educadores que apoiavam suas ideias entendiam que a educação seria a responsável por inserir as pessoas na ordem social. Também conhecido como escolanovismo, a Escola Nova chegou ao País na década de 1920 com as Reformas do Ensino de vários Estados brasileiros (EducaBrasil, 2006).

${ }^{4}$ Esta pedagógica se fundamentara na pesquisa e no trabalho como princípios educativos, em que os jovens passavam duas semanas recebendo conhecimentos gerais e técnicos voltados para a realidade agrícola regional e duas semanas nas propriedades rurais, aplicando os conhecimentos recebidos no tempo presencial (REIS, 2006).

${ }^{5}$ Este autor publicou em 1977 a sua dissertação de mestrado contendo a experiência de 36 anos de existência desta proposta no Brasil.
} 
a materialização de experiências de escolarização articulada à formação profissional, porém elas foram desenvolvidas fora da escola.

Entretanto, a educação escolar formal desenvolvida no período dos anos de 1960-1980 se pautou na perspectiva psicologizante, de base tecnicista e autoritária, pois atendeu ao regime militar da época. Deste modo, a educação da população do meio rural se limitou a proliferação de programas, tais como Programa Intensivo de Preparação de Mão-de-Obra Agrícola (PIPMOA), Programa Diversificado de Ação Comunitária (PRODAC), Serviço Nacional de Formação Profissional Rural (SENAR), Centro Rural Universitário de Treinamento e de Ação Comunitária (CRUTAC), Projeto Rondon, entre outros, os quais apresentavam a perspectiva de formar para o mercado de trabalho urbano.

Nesta mesma linha de pensamento, nos anos de 1970 com a retomada da discussão sobre educação rural foi lançado o II Plano Setorial de Educação (1975-1979), que estabeleceu a criação de condições para o desenvolvimento de programas de educação no meio rural na direção da melhoria socioeconômica das populações dessas áreas, porém sem êxito. E, nos anos de 1980, foi lançado o III Plano de Educação, Cultura e Desporto, que atribuiu à educação um importante papel na política social com a criação do Programa Nacional de Ações Sócio-educativas e Culturais para o meio rural (PRONASEC) e o Programa de Extensão e Melhoria para o meio rural (EDURURAL), porém estes também não obtiveram êxito.

Em contraposição a educação tradicional, tecnicista de caráter psicologizante, houve a mobilização dos movimentos sociais do campo descontente com a permanência do modelo urbano de escola no Brasil, em busca de conhecer a experiência de educação voltada para a realidade do campo por meio de visita às experiências da França ${ }^{6}$ e iniciaram o processo organizativo que viabilizou a criação da Associação das Casas Familiares Rurais NorteNordeste e três associações municipais.

Assim, em 1984 foi trazida para o Brasil a primeira experiência de Casa Familiar Rural estabelecida no Estado do Paraná e de Casa Familiar do Mar, no município de São Francisco do Sul, Estado de Santa Catarina. E em 1994, foi criada a primeira CFR no Estado do Pará, no município de Medicilândia.

\footnotetext{
${ }^{6}$ As escolas em alternância nasceram na França, em 1935, por iniciativa de famílias que se agruparam em associações com duplo objetivo: implementar projetos de desenvolvimento regional e criar alternativas educacionais para os jovens. Para tanto, foi concebido um modelo de escola sob responsabilidade legal, financeira e gerencial a cargo das associações de pais. E as Escolas Famílias Agrícolas (EFAs), foram criadas na Itália, em 1960, com o apoio dos poderes públicos do país.
} 
A filosofia da CFR expressa nos documentos apresenta como princípios centrais: a) gestão coletiva, que implica "na participação das famílias que se responsabilizam junto com os educadores pelo processo formativo, na auto-gestão por uma Associação de Famílias, composta por pais e instituições associadas e, na eleição, em Assembleia Geral, de um Conselho Gestor" (ARCAFAR/PA, 2003, p. 21); b) localização geográfica da escola articulada à concepção de currículo voltado para a realidade do campo, ou seja, as escolas devem estar geograficamente localizadas no meio rural, próximas de seus lotes, para evitar que seus filhos(as) se desloquem, passando o dia inteiro entre o caminho de ida à escola, o período de aulas e o retorno.

Essa pedagogia emergiu devido a existência de inúmeros problemas educacionais no modelo urbano de educação, que vão desde a desvinculação da escola à realidade local, organizada em polos com o funcionamento das escolas em espaço físico urbano com educandos do meio rural, à falta de conhecimento técnico sobre a produção agrícola, o preparo e o uso do solo; à ausência histórica de uma proposta educativa articulada ao desenvolvimento rural com recursos para fomentar as atividades básicas do campo; à despreocupação com o êxodo rural; à falta de escolas, de vagas e de professores com um novo perfil.

A Pedagogia da Alternância tem como objetivo promover a formação integral dos sujeitos do campo apropriada à realidade, tendo como foco a criação de alternativas de geração de renda e a perspectiva do desenvolvimento sustentável, propiciando-lhe condições de fixar-se na terra com qualidade de vida sem sair do campo. Para os atores sociais da região é indispensável uma "formação específica, moderna e voltada às reais necessidades dos agricultores familiares". (ARCAFAR/PA, 2005, p. 6).

As políticas educativas e as práticas docentes inovadoras se fortaleceram com a promulgação da Constituição Federal de 1988, a qual representou um marco para a educação nacional, na medida em que assegurou a educação enquanto direito de todos e dever do estado, como demonstra o seu artigo 205:

A educação, direito de todos e dever do Estado e da família, será promovida e incentivada com a colaboração da sociedade, visando ao pleno desenvolvimento da pessoa, seu preparo para o exercício da cidadania e sua qualificação para o trabalho. (Brasil, 1988).

No texto da Carta Magna, a educação do campo não é mencionada diretamente, contudo, no seu artigo 206 está assegurado que:

O ensino será ministrado com base nos seguintes princípios: I - igualdade de condições para o acesso e permanência na escola; II - liberdade de aprender, ensinar, pesquisar e divulgar o pensamento, a arte e o saber; III - pluralismo de ideias e de 
concepções pedagógicas, e coexistência de instituições públicas e privadas de ensino; IV - gratuidade do ensino público em estabelecimentos oficiais; V valorização dos profissionais do ensino, garantidos, na forma da lei, planos de carreira para o magistério público, com piso salarial profissional e ingresso exclusivamente por concurso público de provas e títulos; VI - gestão democrática do ensino público, na forma da lei; VII - garantia de padrão de qualidade (BRASIL, 1988).

Tais princípios asseguram que as escolas sejam iguais entre si, independentemente da localização, da dependência administrativa e dos sujeitos nela inseridos. Contudo, tais princípios têm sido historicamente desconsiderados nas escolas do campo. Nos anos de 1990, a educação do campo voltou a ser colocada em pauta com a mobilização dos movimentos sociais do campo, que conseguiram colocá-la na agenda política da esfera pública como uma questão de interesse nacional, conforme destaca Di Pierro (2001, p. 06):

Após duas décadas de intensa urbanização e êxodo rural, a temática da educação do campo não ocupou papel relevante na agenda de política educacional durante o período de transição democrática dos anos 80 , e só voltou à pauta do debate político pedagógico nos anos 90 , pelas mãos dos movimentos sociais.

Somou-se a essa luta a aprovação pelo Congresso Nacional, da Lei de Diretrizes e Bases da Educação Nacional (LDBEN) de no 9394/96. Dentre os apontamentos gerais acerca da educação, como a garantia desta enquanto direito público subjetivo, houve um avanço considerável no que concerne ao reconhecimento da especificidade da educação do campo, como podemos ver no artigo 28 :

\footnotetext{
$\mathrm{Na}$ oferta de educação básica para a população rural, os sistemas de ensino promoverão as adaptações necessárias à sua adequação às peculiaridades da vida rural e década região, especialmente:

I - conteúdos curriculares e metodologias apropriadas às reais necessidades e interesses dos alunos da zona rural;

II - organização escolar própria, incluindo adequação do calendário escolar às fases do ciclo agrícola e às condições climáticas;

III - adequação à natureza do trabalho na zona rural (Brasil, 1996).
}

Em que pese o reconhecimento, a aplicação de tais diretrizes ainda não se concretizou de fato em grande parte das escolas que existem no campo. Neste contexto, foi criado o Movimento nacional Por Uma Educação do Campo, o qual teve como marco o I Encontro Nacional de Educadoras e Educadores da reforma agrária (ENERA), em 1997.

Esse encontro foi desenvolvido por instituições como: Movimento dos Trabalhadores Rurais Sem Terra (MST), Universidade de Brasília (UnB), Conferência Nacional dos Bispos do Brasil (CNBB), Fundo das Nações Unidas para a Infância_(UNICEF), Organização das Nações Unidas para a Educação, a Ciência e a Cultura (UNESCO), que lançaram o desafio de 
desenvolverem estratégias educativas amplas, de acordo com o contexto do campo, levando em conta as suas especificidades. Neste contexto, a educação do campo passou a ser:

\begin{abstract}
(...) um conceito novo [...] que nasceu dos movimentos sociais e organizações sociais do campo, surgiu do meio das lutas de quem não se conforma com as coisas como estão. É um dizer que surgiu do meio dos sem terra, dos pequenos agricultores, dos atingidos por barragens, das mulheres camponesas, da juventude do campo, do meio das pastorais. E surgiu com a ajuda de muitos estudiosos da educação brasileira que estão nas universidades, em órgãos públicos, educadores e educadoras que estão junto com o nosso povo do campo também lutando no campo da educação (VIA CAMPESINA, 2006: 13-14).
\end{abstract}

Em 2002, foi aprovada a Resolução CNE/ CEB N ${ }^{o}$ 1, de 03 de Abril de 2002, que instituiu as Diretrizes Operacionais para a Educação Básica nas Escolas do Campo, sem dúvida o mais significativo marco legal da história da educação do campo em nosso país.

As Diretrizes Operacionais para a Educação Básica nas Escolas do Campo são compostas por 16 artigos com normas políticas, pedagógicas, administrativas e financeiras a serem observadas nos projetos das instituições que integram os diversos sistemas de ensino municipal, estadual e federal, em todos os níveis e modalidades de ensino. Já sobre o Grupo Permanente de Trabalho de Educação do Campo, Ramos et al. afirmam:

(...)] com a atribuição de articular as ações do Ministério pertinentes à educação do campo, divulgar, debater e esclarecer as Diretrizes Operacionais para a Educação Básica nas Escolas do Campo [...], e apoiar a realização de seminários nacionais e estaduais para a implementação dessas ações. (Ramos et al, 2004, p. 08).

O acúmulo do debate trouxe à tona a diferença entre a Educação Rural e Educação do Campo, pois elas não são sinônimas, mas sim possuem diferenças substanciais advindos da origem de paradigmas distintos que envolve o contexto sócio-político-cultural e educacional no meio rural. Segundo Fernandes e Molina (2004) as diferenças básicas desses paradigmas são os espaços onde são construídos e seus protagonistas, ou seja, a educação rural é resultado de um projeto criado para a população do campo e a educação do campo foi criada pelas populações do campo.

O termo Educação Rural em geral encontra-se vinculada a uma ideia marginalizada do campo. Trata-se de uma expressão carregada de preconceitos e conservadorismo, porque é pensada para o povo do campo, possui uma perspectiva unidimensional, que ignora a identidade do campo e as demandas sociais dos sujeitos, ao mesmo tempo em que está associada a uma visão unicamente econômica e ignora a organização social no campo e o protagonismo dos sujeitos em seu processo de escolarização (Fernandes e Molina, 2004). 
A Educação do Campo é um movimento fundamentado pela luta social e por experiências educativas inovadoras, portanto uma perspectiva diferenciada por ser desenvolvida pela coletividade, a partir da visão do campo enquanto espaço heterogêneo, plural, político, possuidor de identidade e demandas distintas, na qual os sujeitos do campo são protagonistas. Esse movimento compreende a relação campo-cidade enquanto um processo de interdependência e se manifesta inconformada com a situação de abandono em que o meio rural encontra-se submetido e a educação como um elemento fundamental para transformação humana, social, política, econômica, ambiental para se alcançar o desenvolvimento sustentável.

A educação do campo se fundamenta na expressão do e no campo, em que no campo, indica a necessidade da escola estar localizada no espaço geográfico, político e social do campo, possibilitando a apropriação e sistematização do conhecimento produzido no âmbito da ciência; e, do campo, representa a educação construída/produzida com as populações do campo, a partir de seus interesses e necessidades, implicando na estruturação de um currículo que priorize e valorize os valores expressos por essas populações e pressupõe a participação efetiva e crítica dos sujeitos, enquanto produtores de sua história, com acúmulo de conhecimento sobre a vida e o meio em que vivem e trabalham.

Essa concepção está fundada na indissociabilidade entre as políticas públicas, a educação e a pesquisa; a cidadania, o campo e a produção, em que nas tríades CampoPolíticas Públicas-Educação (Cardalt, 2002 e Molina, 2003) e Produção-CidadaniaPesquisa (Michelotti, 2007) há destaque para a fusão social escolar, que se refere a necessidade de ajudar construir um projeto de campo.

$\mathrm{Na}$ concepção de campo, a forma de produção está baseada na cooperação entre os agricultores para produção em três níveis: para o próprio consumo, para a comercialização nas cidades próximas e para comercialização em polos comerciais mais distantes. Daí ser necessário promover e reivindicar políticas públicas e ações que viabilizem a educação, a assistência técnica e o crédito financeiro. Nessa perspectiva, a dimensão da pesquisa, apontada por Michelotti (2007), é assumida como estratégia e princípio educativo e ainda como impulsionadora da produção do conhecimento vinculada ao trabalho no campo, onde a educação do e no campo contribui a produção de base agroecológica e contribui para afirmar a cidadania (SCALABRIN, 2011).

Por esse viés, a escola do campo deve contribuir na elaboração de políticas públicas com base na relação entre o conhecimento da realidade, o conhecimento dos educandos e o conhecimento das diferentes áreas (a educação, a sociologia, a economia, a agronomia, a 
política, a história, a filosofia), e, assim, configurar o rural como um lócus transdisciplinar de produção e sistematização de conhecimento, ancorado na heterogeneidade, dinamismo e diversidade, cujo projeto de desenvolvimento é centralidade na produção camponesa (SCALABRIN, 2011).

Outro aspecto a ser superado é a dicotomia entre campo e cidade, pois "a discussão sobre o que é rural é antiga na Sociologia. Até os anos 70, predominava uma abordagem dualista nesta conceituação, isto é, rural e urbano eram vistos como duas realidades rivais que coexistiam paralelas e independentes uma da outra" e restrito a produção agrícola. Por isso, alguns estudiosos chegaram a encontrar nessa dicotomia um dos principais fatores do subdesenvolvimento: o rural seria pobre atrasado porque toda a política estaria voltada para os interesses urbanos.

Nos anos de 1960 e 1970 esta visão dualista rural-urbano passou a ser considerada inadequada. Pesquisadores do tema passaram a ver o rural e urbano como sendo duas partes inter-relacionadas de um único "todo" e como "sociedade global", onde teríamos, na história três formas de sociedade global: a tribal, a agrária e a urbana.

Observa-se que a inferioridade foi construída pelos interesses de cunho político e econômico, visto que:

Na sociedade agrária, a cidade existe como um centro político-administrativo que organiza e domina o meio rural, mas é inteiramente estruturada pelo rural. Ou seja, há uma predominância do rural sobre o urbano. O campo é o setor produtivo, e o urbano é o consumidor. A maior parte da população está envolvida na produção (em torno de 20 camponeses alimentam um citadino). As relações sociais, embora sejam mescladas por relações indiretas e indiferentes, ainda predomina a afetividade sobre o racional (TREVIZAN, 2000, p. 12).

Essa perspectiva mudou com a ascensão da sociedade urbana e, com ela, a crença no fim do trabalho agrícola e do próprio campo, que seria substituído pela produção industrial. Embora essa visão não tenha se concretizado, observa-se que,

Na sociedade urbana, a partir da revolução industrial, a cidade começa a se libertar, do ponto de vista econômico, da dependência com o rural, em função do desenvolvimento tecnológico que permitiu a produção de alimentos no urbano. A sociedade se tornou, então, produtora por excelência e teria passado a impor sobre o rural seu modo de vida. Aqui, a maior parte da população se ocupa com a indústria e serviços, e vive na cidade. Agora, um agricultor garante a subsistência de seis citadinos. As relações sociais se tornam mais e mais indiretas e indiferentes do ponto de vista emocional. O urbano passou, então a ser visto como o espaço de produção industrial e oferta de serviços, enquanto que o rural o espaço de produção agrícola (TREVIZAN, 2000, p. 12).

Diante do acúmulo histórico das discussões e pesquisas em torno dos conceitos sobre o rural e o urbano, sobre a educação rural e a educação do campo, os princípios, conceitos e 
concepção da educação do campo, torna-se fundamental mudar a o papel da escola do campo, o que perpassa pela proposta curricular, política e metodológica. Nesta perspectiva, a função social da escola requer a construção de um conhecimento que contribua para a construção do projeto de campo, o qual considere os conhecimentos dos sujeitos e compreenda o necessário acesso ao conhecimento sistematizado, as técnicas e tecnologias para viver e produzir no campo de modo sustentável, pois segundo Cortella (2008, p 17):

O universo vivencial da classe trabalhadora é extremamente rico em termos de cultura, mas precário em termos de conhecimentos mais elaborados, que são propriedade quase que exclusiva das elites sociais que dificultam ao máximo o acesso da classe trabalhadora a esta forma de conhecimento eficaz.

Para esse autor, o conhecimento possui uma construção cultural (social e histórico), pois os seus valores dependem dos seres humanos para se realizarem. São os humanos que os elaboram e atribuem significados, os quais são moldados pela cultura (pela sociedade e pela história dessa cultura). Por isso, a produção do conhecimento, historicamente, tem ênfase relacionada com as necessidades de sobrevivência (SCALABRIN, 2011).

Dada essa realidade, as consequências da não observância da população que vive no campo, no que tange ao acesso à educação, continuou produzido resultados socioeconômicos irreparáveis, uma vez que há ausência de escola no campo, e aonde há escola estas desenvolvem uma formação não condizente com a realidade do campo e as especificidades do seu processo produtivo, tendo como consequência os baixos índices de produtividade pelo uso de técnicas inadequadas à realidade de cada região.

Apesar do contexto educacional brasileiro apresentar iniciativas voltadas à educação do campo, algumas mantiveram o enfoque instrumental do conhecimento, e outras, que reconhecem as particularidades culturais e as singularidades das populações do campo, no entanto ainda não houve políticas públicas de educação capaz de atender as reais necessidades destas populações, pois as escolas existentes no campo continuam a desenvolver uma organização escolar, um calendário e um currículo urbanocêntrico, ou seja, igual ao da cidade.

As experiências no âmbito da educação pública que desenvolve um projeto educacional inovador, por fundamentar-se nos princípios da pedagogia da alternância, no currículo ético-crítico que tem a realidade como objeto de conhecimento, tem sido organizado por eixos temáticos que aglutinam os componentes curriculares e/ou por tema gerador de referência italiana e francesa ou freireana.

De modo geral, a Pedagogia da Alternância pauta-se na experiência prática do estudante, com o conhecimento empírico e a troca de conhecimento com atores do sistema 
tradicional de educação, e, também, com membros da família e da comunidade na qual vivem os educandos, o que lhes fornece ensinamentos sobre própria realidade.

A política pública educacional, a partir de uma mudança paradigmática, que dispõe a pedagogia da alternância como alternativa de escolarização para o meio rural, requer o acesso e a permanência do jovem na escola por um período de tempo e, noutro, a permanência na família para continuar a produzir e também inserir técnica e tecnologias no processo familiar durante o curso, com vistas a não se distanciar da vida e cultura local, bem como contribuir na melhoria do processo produtivo. Isso requer uma proposta curricular interdisciplinar e integrada capaz de fazer uma revisão crítica dos conteúdos e métodos usados na escola e uma posição política quanto a educação desenvolvida, a qual deve assegurar o acesso e permanência com qualidade.

\section{BASES FILOSÓFICAS DO CAMPUS RURAL DE MARABÁ/IFPA}

O Campus Rural de Marabá (CRMB) ${ }^{7}$ tem origem na mobilização e organização da luta por condições favoráveis ao desenvolvimento e sustentabilidade da produção familiar no Sudeste paraense e pela educação. A materialização desta mobilização regional coletiva possibilitou que a construção da estrutura física do campus fosse edificada dentro de um assentamento da reforma agrária, atendendo, essencialmente, as populações de origem rural, indígena e professores das escolas do campo, tendo como missão:

Promover a educação profissional e tecnológica em diferentes níveis e modalidades,
sobretudo técnico integrado com o ensino médio, dos povos do campo da
mesorregião do sudeste do Pará, em atendimento as suas demandas sociais,
econômicas e culturais e em sintonia com a consolidação e o fortalecimento de suas
potencialidades, estimulando a pesquisa com vistas à geração e difusão de
conhecimentos, privilegiando os mecanismos do desenvolvimento sustentável e
promovendo a inclusão social, a cidadania e o desenvolvimento regional (IFPA,
2010, p. 02).

Assim, a construção do Projeto político-pedagógico teve sua primeira versão elaborada pelas instituições e movimentos sociais do campo que compunham o Fórum Regional de Educação do Campo, no ano de 2010, e fora revisado pelos servidores do campus em 2012 e 2016, a partir da implementação da educação do campo como política pública.

\footnotetext{
${ }^{7}$ Com a expansão da Rede Federal de Educação Profissional, Científica e Tecnológica (Lei n ${ }^{\circ}$ 11.892, de 29.12.2008), foi criado o Instituto Federal de Educação, Ciência e Tecnologia (IFPA), a partir da integração do Centro Federal de Educação Tecnológica do Pará (CEFET-PA) e das Escolas Agrotécnicas Federais de Castanhal (EAFC) e de Marabá (EAFMB) o qual, atualmente possui 12 campi, dentre eles o Campus Industrial de Marabá.
} 
E foi com essa intencionalidade que o Campus Rural de Marabá/IFPA se pôs a "provocar, por meio da política de formação continuada para servidores do referido campus", para desenvolver a organização curricular via tema gerador articulada com os princípios da Pedagogia da Alternância. Atendendo a essa missão, o CRMB buscou qualificar as populações do campo por cursos que atendem as demandas sociais, tendo desenvolvido inúmeros cursos junto as populações indígenas e camponesas, nos seguintes níveis e modalidades:

- Curso Técnico em Agricultura Familiar integrado ao Ensino Fundamental, ofertado na forma concomitante para estudantes de EJA, em parceria com as Prefeituras Municipais;

- curso Técnico em Agropecuária intergado ao Ensino Médio voltado para jovens e adultos do campo;

- curso Técnico Agroecologia integrado ao Ensino Médio voltado às populações indígenas do Sudeste do Pará e de Jacareacanga;

- curso de Enfermagem Intergados ao Ensino Médio voltado às populações indígenas de Jacareacanga;

- curso de Magistério indígena voltado às populações indígenas de Jacareacanga;

- curso Subsequente em Agropecuária voltado aos jovens do campo;

- curso Subsequente e Agroindústria voltados aos jovens do campo;

- cursos Subsequente em Turismo, Pesca e Informática voltados aos jovens do campo de Vigia de Nazaré-Pará;

- curso de Licenciatura em Educação do Campo voltado aos professores das escolas do campo;

- curso superior de Agroecologia voltado aos jovens do campo;

- curso de Especializações em Educação do Campo, Agroecologia e Questões Pedagógicas voltados aos servidores do CRMB;

- curso de Especializações em Educação do Campo, Agricultura Familiar e Sustentabilidade na Amazônia voltados para professores atuantes na Educação de Jovens e Adultos;

- curso de Especializações em Educação do Campo, Agricultura Familiar e Currículo voltados para professores que atuam na multissérie;

- curso de Especialização em Recuperação de Áreas Degradadas e Alteradas, voltados às populações do campo;

- inúmeros cursos de formação profissional de curta duração voltados para agricultores.

Assim, após dez anos de sua criação o campus oportunizou uma formação adequada ao meio rural, abrangendo mais de 1.500 sujeitos do campo.

A proposta pedagógica do Campus Rural de Marabá (CRMB) foi construída no período de março de 2010 a março de 2016, por meio da formação continuada de servidores, a 
qual possibilitou o desenvolvimento da proposta curricular e metodológica fundamentada nos princípios e concepção da Educação do Campo, da Agroecologia, da Pedagogia da Alternância e do currículo interdisciplinar e intergado.

Assim, a formação do quadro de servidores atendeu a política de desenvolvimento institucional, envolvendo a comunidade escolar, no sentido de favorecer a socialização dos planos de ações e metas, do planejamento estratégico e de gestão, bem como a afinação da equipe no que se refere à proposta de escola e de educação na região onde o CRMB está inserido. A intencionalidade da formação esteve em garantir uma atuação fundamentada na relação ensino-pesquisa-extensão e teoria-prática como dimensões intrínsecas (FREIRE, 1981) e a formação crítico-criativo comprometida com os princípios de uma educação emancipatória e da Agroecologia que assume uma dimensão estratégica.

No que se refere a formação de professores das escolas dos campo, tanto a licenciatura quanto as especializações, o CRMB pretendeu provocar o poder público local a conhecer a Legislação da Educação do Campo, bem como inseri-la na política educativa local e, por conseguinte, nas escolas do campo.

No que refere a formação dos jovens filhos de agricultores e agricultores, o campus buscou a consolidação do currículo interdisciplinar e integrado entre Ensino Médio e Formação Técnica, capaz de garantir a voz dos sujeitos no currículo, assegurando assim uma qualificação que atenda suas demandas, interesses e necessidades oriundas dos processos produtivos do campo e suas formas de vida.

No que se refere a formação de povos indígenas no Sudeste do Pará e em Jacareacanga, além dos elementos acima referidos para os cursos técnicos intergados, a formação requer assegurar a legislação específica destes povos no desenvolvimento de sua educação em conjunto com eles, bem como oportunizar o acesso a escola sem sair da aldeia. Segundo Scalabrin (2011) a fragmentação do conhecimento não se restringe apenas a existência das disciplinas trabalhadas como caixinhas isoladas, mas também na superioridade do conhecimento científico e na negação dos conhecimentos tradicionais, populares, empíricos, dos sujeitos.

A presente proposta pedagógica do CRMB buscou reafirmar a educação como direito constitucional cujo fundamento se referência na legislação brasileira, bem como nas diversas experiências educativas desenvolvidas a partir das parcerias entre organizações de trabalhadores rurais, Organizações Não Governamentais e Instituições Públicas Federais que têm se empenhado em debater e elaborar propostas regionalizadas de políticas de desenvolvimento do campo. 
Nesse sentido, atende os preceitos da LDB 9394/96 no que se refere aos Artigos 23 e 28 , bem como as diretrizes operacionais das escolas do campo e indígenas, propondo e desenvolvendo políticas públicas educativas de atendimento das pessoas que vivem e trabalham no campo, no sentido de garantir o acesso à educação observando as diferenciações próprias da realidade do campo e de seus sujeitos.

A formação no tocante ao ensino médio integrado a formação profissional assegura a organização de itinerários formativos que possibilita aos estudantes o domínio de conhecimentos técnicos-científicos combinados a uma sólida formação humana e assume o currículo interdisciplinar e integrado fundamentado na problematização da realidade no diálogo entre conhecimentos (populares e científicos) e valorize as trajetória individuais e coletivas como expressão da cultura.

Nesta perspectiva, a proposta curricular desenvolvida nos anos de 2011- 2015 fundamentou-se na proposta curricular via tema gerador ${ }^{8}$, sendo referência freireana, cuja essência está explicita no terceiro capítulo da obra Pedagogia do Oprimido (1975). A visão de educação deste autor se fundamente na ideia sobre a necessidade do estabelecimento do diálogo com o outro, pautado na problematização da realidade social, para o que se faz fundamental o exercício cotidiano de práticas docentes interdisciplinares e integradas.

Nessa linha de pensamento, a proposta freireana se articula com ouros autores, como Severino (1995) e Santomé (1988) e Ramos (2005), entre outros.

Para Severino (1995), o termo interdisciplinaridade surge ligado à necessidade de superação da esterilidade acarretada pela ciência excessivamente compartimentada e sem comunicação entre os diversos campos. O que, então, poderia ser reservado à inter-relação de diferentes campos do conhecimento com finalidades de pesquisa ou de solução de problemas, sem que as estruturas de cada área do conhecimento sejam necessariamente afetadas em consequência dessa colaboração.

Segundo o autor, o sentido do interdisciplinar precisa ser redimensionado quando se trata do saber teórico, pois ele precisa ser construído quando se trata do fazer prático. E, na medida em que são rompidas as fronteiras entre as disciplina, mediações do saber, na teoria e na pesquisa, impõe-se considerar que a interdisciplinaridade é condição também da prática social.

\footnotetext{
${ }^{8} \mathrm{O}$ tema gerador parte da realidade na visão dos sujeitos da localidade e é apresentado em falas que trazem uma situação-limite social. Para Freire (1981) uma situação-limite é aquela vivida pela comunidade que precisa ser superada para não sucumbir.
} 
Para Santomé (1998), o currículo integrado tem sido utilizado na tentativa de contemplar uma compreensão global do conhecimento e de promover maiores parcelas de interdisciplinaridade na sua construção, de modo que o termo interdisciplinaridade surge ligado à necessidade de superação da esterilidade acarretada pela ciência excessivamente compartimentada e sem comunicação entre os diversos campos.

Assim, requer a inter-relação de diferentes campos do conhecimento com finalidades de pesquisa ou de solução de problemas, sem que as estruturas de cada área do conhecimento sejam necessariamente afetadas em consequência dessa colaboração. A integração, por sua vez, ressalta a unidade que deve existir entre as diferentes disciplinas e formas de conhecimento nas instituições escolares.

Já para Ramos (2005, p. 20), a integração incorpora elementos de análises anteriores e se definem finalidades específicas durante o percurso formativo, possibilitando as pessoas compreender a realidade para além de sua aparência fenomênica, pois "os conteúdos de ensino não têm fins em si mesmos nem se limitam a insumos para o desenvolvimento de competências.", eles são "conceitos e teorias que constituem sínteses da apropriação histórica da realidade material e social pelo homem".

Neste sentido, o currículo ético-crítico rompe com a concepção instrumental do conhecimento em que os conteúdos são visto como objeto do conhecimento para adaptação ao contexto social e somente os estudantes são vistos como sujeitos do processo educativo. Por outro lado, defender a concepção ético-crítica do conhecimento, requer a compreensão de que a realidade é objeto de conhecimento; educadores, educandos e comunidade são vistos como sujeitos, de modo que o acesso ao conhecimento científico é fundamental para a transformação do contexto sócio-histórico (SCALABRIN, 2011).

Nessa perspectiva, as situações-limite social tornam-se estruturantes do currículo, pois são situações que desafiam a prática dos seres humanos de tal forma que se torna necessário enfrentá-las e superá-las para prosseguir. Assim, o trabalho de decodificação requer "uma revisão crítica dos conteúdos e métodos usados na escola (...)", a partir de três elementos igualmente fundamentais: a realidade local, o conhecimento escolhido para ser ensinado e o processo de aprendizagem a partir da construção do conhecimento entre áreas, sobre a localidade e do educando se inter-relacionam (PERNAMBUCO; PAIVA, 2006).

Com base no arrazoado, a construção coletiva do currículo tem como elemento fundamental o conhecimento da realidade por parte dos professores, requer que a organização do conhecimento se dê de forma também coletiva, por meio da problematização e da tematização para uma aplicação do conhecimento ressignificado. 
Nesse processo, há não apenas uma inversão da lógica de seleção dos conteúdos; mas muda-se também a forma de "entrada" dos professores, que não se dá mais do conteúdo pelo conteúdo ou horários fixados em dias da semana, mas sim dos tópicos/temáticas da programação de ensino em que os professores de cada área e disciplina "entram" para provocar a problematização junto aos estudantes no sentido de os ajudar a compreender a realidade, para em seguida realizar o aprofundamento teórico, que gerara ação de intervenção na realidade para transformá-la.

Sendo assim, o tempo das aulas e a forma de entrada dos docentes em um curso deve, necessariamente, considerar as deliberações do planejamento coletivo, seguindo a sequência lógica da construção e da apropriação do conhecimento com vista a atender o processo de aprendizagem. Desse modo, o Plano de Aula segue uma dada estrutura que visa oportunizar o diálogo, partindo sempre da realidade para promover o aprofundamento teórico, composto por técnicas para abordar os conhecimentos e conteúdos selecionados a partir do detalhamento, até chegar ao Plano de ação, com proposição de atividades que levem o grupo a formular práticas de transformações na realidade local.

Um dos elementos centrais para a viabilização do currículo interdisciplinar e integrado está no planejamento coletivo capaz de desenvolver "uma revisão crítica dos conteúdos e métodos usados na escola (...)", a partir de três elementos igualmente fundamentais: a realidade local, o conhecimento escolhido para ser ensinado e o processo de aprendizagem (PERNAMBUCO e PAIVA, 2006).

No CRMB, o espaço de formação continuada dos servidores se materializou com a participação de professores e técnicos diretamente envolvidos com o percurso formativo do curso, por meio da Especialização (2010-2013) e da formação continuada (2013-2015), que oportunizou estudos, planejamento coletivo e reflexão das práticas docentes vivenciadas, seguida de elaboração da programação de ensino e do plano de aula.

\section{AS PRÁTICAS VIVENCIADAS NO CRMB: CURSOS DE AGROECOLOGIA E AGROPECUÁRIA INTEGRADOS AO ENSINO MÉDIO}

O estudo dos relatórios da formação continuada desenvolvida no período de 20102012 por meio da Especialização em Educação do campo, Agroecologia e Questões Pedagógicas, bem como pelos encontros de formação semestrais, ambos conduzidos pela 
assessoria externa ${ }^{9}$ e também a análise dos planos de aula, demonstrou que no CRMB se criou uma nova forma de organização curricular, como também uma nova forma de seleção de conhecimentos e conteúdos que parte da visão dos sujeitos do campo e suas necessidades, consequentemente, a seleção leva em conta aquilo que tem uso social na vida do campo.

Essa nova forma apresenta dois elementos centrais: o estudo da realidade e a organização do conhecimento desenvolvido processualmente pela coletividade que compõe o corpo docente, com vista a aplicação do conhecimento significativo pelo diálogo entre educador/educando e educando/comunidade, levando em conta os conhecimentos da realidade, dos educandos e das áreas do conhecimento.

O estudo da realidade foi composto pela roda de conversa nas aldeias com participação dos estudantes e das lideranças indígenas. Já nas comunidades rurais se deu com a visita às famílias agricultoras para conhecer os que elas pensam sobre a realidade em que vivem, bem como pelo estudo de materiais secundários que contém informações sobre a história da localidade e o diagnóstico social e produtivo de cada localidade onde residem os estudantes.

A organização do conhecimento ocorreu pelos encontros dos professores para assistirem aos vídeos, fruto da visita/rodas de conversas a nove aldeias para seleção das falas que continham situações-limite social, seguida da construção do contra-tema e da programação de ensino (ver anexo I) e dos planos de aula semestrais. Vale resaltar que havia um único tema Gerador, porém uma programação de ensino para cada área de conhecimento, composta por mais de uma fala significativa.

Além disso, havia reuniões dos professores por área (as quais antecediam cada alternância) para rever o plano de aula e definir o que seria desenvolvido em cada disciplina naquela alternância, seguida da socialização composta pela apresentação dos conhecimentos a serem trabalhados por cada área aos professores de todas as áreas que atuariam naquela etapa, com vista a evitar sombreamento de conteúdos e assegurar a sequência necessária, a continuidade e a integração.

\footnotetext{
9 Essa formação continuada foi desenvolvida pela Diretoria de Ensino do Campus Rural de Marabá com apoio dos educadores Marta Castanho Pernambuco () e Antonio Gouvea da Silva no período entre agosto de 2011 e janeiro de 2015 através de uma semana de formação (composta por estudo de temas relacionados a educação, ao ensino e o currículo, pela construção coletiva do currículo vi tema gerador de base freireana e dos planos de aula semestrais) realizada nos meses de janeiro e agosto de cada ano e teve como objetivo desenvolver a proposta curricular interdisciplinar e integrada via tema gerador no curso de Agroecologia integrado ao Ensino Médio voltada aos povos indígenas. Dada a sua riqueza e sucesso no processo de formação, a mesma também passou a ser desenvolvida no curso de Agropecuária integrado entre 2014 e 2015.
} 
A aplicação do conhecimento ocorria a partir da entrada dos professores por área, considerando o foco de cada ciclo e a maior integração entre áreas, de modo a evitar o grande número de disciplinas ao longo do curso, a fragmentação do conhecimento e a lógica conteudista pautada na decoração e na avaliação como controle da aprendizagem e punição dos estudantes. O mesmo processo foi realizado no curso de agropecuária integrado, porém com visitas as famílias de doze assentamentos da região sudeste do Pará de onde os estudantes do curso de Agropecuária eram oriundos.

Nessa perspectiva, a pesquisa demonstrou que o percurso formativo interdisciplinar e integrado dos professores oportunizou a ação docente interdisciplinar em cada área, com maior avanço nas áreas a das Ciências Agrárias e das Ciências da Natureza e Matemática devido uma clara e profunda integração entre as áreas das Ciências Humanas e Ciências Agrárias nos I e III ciclos do curso ${ }^{10}$; e também entre Ciências da Natureza/Matemática e Ciências Agrárias no II ciclo.

Essa integração se efetivou pelo diálogo processual tanto no planejamento quanto no desenvolvimento das práticas docente, as quais estiveram imbricadas de uma relação intrínseca entre teoria e prática e ensino, pesquisa e extensão, a partir de diferentes tempos e espaços formativos na escola e na aldeia ou comunidades rurais. Tal processo gerou qualidade na formação escolar dos estudantes capaz de fomentar o processo produtivo no campo baseado pela elaboração de sínteses e projetos, atendendo as demandas locais em práticas agroecológicas, por meio da investigação da realidade e da experimentação sócio-produtiva.

O desenvolvimento desse processo não foi apropriado por todos os professores do quadro docente a época, de modo que a proposta de currículo via tema gerador interdisciplinar e integrado foi retirado do Projeto político-pedagógico do campus na sua ultima recisão, voltando a utilizar somente o currículo estruturado por eixo temático. Observou-se, porém, maior dificuldade de atuação interdisciplinar entre os professores das áreas das Ciências Humanas e da Linguagem (Língua Portuguesa, Arte, Informática e Educação Física).

A análise do ultimo relatório do ano de 2015 possibilitou identificar que a proposta curricular via tema gerador não foi apropriado por todos os professores do quadro docente a época, seja pela falta de comprometimento de alguns, como pode ser observado nos itens 1,2 , $3,7,8,9$ e 10 expressas no quadro a seguir, seja pela resistência dos novos profissionais que

\footnotetext{
${ }^{10} \mathrm{O}$ curso técnico em Agroecologia está organizado em 3 (três) ciclos de estudo com diferente temporalidade, assim caracterizados: Ciclo 1: As dimensões históricas e identitária dos povos do Campo e o estudo do Lote com duração de 1 (um) ano; Ciclo 2: Os agroecossistemas e a sustentabilidade no campo, com duração de 1 (um) ano e meio; e, ciclo 3: Desenvolvimento, agricultura familiar camponesa e educação do campo, com duração de seis meses..
} 
adentravam à instituição, conforme item 4, os quais vindos de outras regiões do estado ou do país não possuíam experiência sobre os eixos que estruturam a proposta institucional do CRMB, ou atuação nas instituições não escolares de caráter inovador como as EFAS e as CFRs, por exemplo; tão pouco formação teórica ou domínio conceitual sobre os mesmos .

Isso implicou na baixa de qualidade de ensino no curso, expressa na repetência e evasão crescente ano a ano, saindo de uma escala de até 10\% em 2014 para 40\% em 2017. Além disso, a dificuldade de manutenção de uma infraestrutura de qualidade na escola do campo, pela ausência de políticas públicas no campo, conforme exposto no item 5 , prejudica o trabalho nas salas de aula e laboratórios, o que, por vezes, leva os professores a não realizar atividades práticas.

Somado a isso, encontra-se os processos seletivos em concursos desenvolvidos pelo IFPA, de base conteudista, centrado em áreas fechadas que não atendem a realidade e que não asseguram critérios com base na realidade local onde se encontram cada um de seus 18 Campis e suas especificidades de cursos e público. Isso tem gerado a contratação de professores desprovidos de conhecimento sobre o Pará e as regiões onde os campi se encontram, enfrentam dificuldades que vão desde adaptação a nova morada até a incompreensão de conceitos centrais que compõem o IFPA e o CRMB, conforme expresso no item 11 .

Quadro 1: Problemas e dificuldades vivenciadas no processo formativo docente do CRMB, e necessidades de superação

\begin{tabular}{|c|c|}
\hline $\begin{array}{l}\text { PROBLEMAS /DIFICULDADES } \\
\text { VIVENCIADAS }\end{array}$ & NECESSIDADE \\
\hline $\begin{array}{l}\text { 1.Ausência parcial ou total de professores nos } \\
\text { momentos de formação continuada. } \\
\text { Isso tem gerado descontinuidade no percurso } \\
\text { formativo do discente, prejuízo à ação docente das } \\
\text { áreas da linguagem, refletindo negativamente no } \\
\text { aprendizado. }\end{array}$ & \multirow[t]{2}{*}{$\begin{array}{l}\text { Equipe de educadores (professores e técnicos) } \\
\text { participando integralmente da formação continuada e } \\
\text { materializando as proposições coletivas construídas } \\
\text { coletivamente nos momentos de planejamento, } \\
\text { elaboração individual do plano de aula e socialização } \\
\text { na área e entre áreas. }\end{array}$} \\
\hline $\begin{array}{l}\text { 2.Ausência de Planos de aula por parte de alguns } \\
\text { professores, o que ocasiona prejuízo ao processo de } \\
\text { acompanhamento da equipe pedagógica e ao } \\
\text { diálogo docente no processo de efetivação da } \\
\text { integração. }\end{array}$ & \\
\hline $\begin{array}{l}\text { 3.Abandono parcial das temáticas, conteúdos e } \\
\text { ações propostas por cada área nos momentos de } \\
\text { planejamento, por parte de alguns professores. } \\
\text { Isso vem gerando insatisfações de alunos e } \\
\text { professores. }\end{array}$ & $\begin{array}{l}\text { Seguir a programação de Ensino proposta e efetivar as } \\
\text { ações a partir daquilo que foi acordado coletivamente } \\
\text { na área e entre áreas, de modo a oportunizar um } \\
\text { processo de construção de conhecimento aos } \\
\text { estudantes; }\end{array}$ \\
\hline $\begin{array}{l}\text { 4. Resistência proposta pedagógica em curso, pois a } \\
\text { mesma requer participação de todos os docentes e }\end{array}$ & 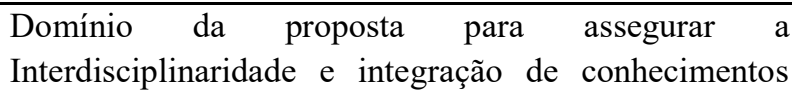 \\
\hline
\end{tabular}




\begin{tabular}{|c|c|}
\hline $\begin{array}{l}\text { comprometimento com a educação. } \\
\text { Isso tem ocorrido, devido a rotatividade da equipe } \\
\text { que atinge: } 70 \% \text { do quadro de professores e } 40 \% \text { no } \\
\text { quadro técnico. } \\
\text { Isso ocorre devido a ausência de critérios nos } \\
\text { processos seletivos docentes e técnicos } \\
\text { desenvolvidos pelo IFPA. }\end{array}$ & entre as disciplinas de cada área e entre áreas. \\
\hline $\begin{array}{l}\text { 5.Atraso na conclusão das obras no CRMB, o que } \\
\text { incidem diretamente na falta de água, energia e } \\
\text { internet, danifica aparelhos e equipamentos, } \\
\text { consequentemente, prejudica o trabalho } \\
\text { desenvolvido em sala de aula }\end{array}$ & $\begin{array}{l}\text { Espaço adequado e com condições de trabalho da } \\
\text { equipe de educadores (professores e técnicos) nos } \\
\text { espaços de trabalho de sala de aula e de campo nas } \\
\text { Unidades Integradas de Ensino/Pesquisa/Extensão. }\end{array}$ \\
\hline $\begin{array}{l}\text { 6.Pouca participação dos professores e técnicos nas } \\
\text { visitas de Tempos-comunidade (TCs) e nos } \\
\text { seminários de socialização das pesquisas realizadas } \\
\text { pelos estudantes e sistematizada e socializada no } \\
\text { início da etapa para ser utilizada e aprofundada no } \\
\text { decorrer de cada Tempo escola e por todos os } \\
\text { professores, a partir das questões presente no plano } \\
\text { de pesquisa, estudo e trabalho de cada tempo } \\
\text { comunidade. } \\
\text { Isso tem gerado o aprofundamento parcial dos } \\
\text { dados das pesquisas, consequentemente, a não } \\
\text { solução aos problemas levantados pelas pesquisas } \\
\text { discentes. }\end{array}$ & $\begin{array}{l}\text { Participação integral da coordenação e socialização } \\
\text { com os demais membros da equipe; } \\
\text { Observação constante e anotação das falas da } \\
\text { comunidade e dos educandos (que expressem uma } \\
\text { situação-limite) em todos os momentos de realização } \\
\text { das atividades de TCs. }\end{array}$ \\
\hline $\begin{array}{l}\text { 7.Participação pontual de alguns professores e } \\
\text { técnicos ligados ao ensino nas oficinas de } \\
\text { planejamento coletivo, o que gera incompreensão } \\
\text { sobre o processo em curso. }\end{array}$ & $\begin{array}{l}\text { Todas as ações envolvendo todos os sujeitos devem } \\
\text { tomar como ponto de partida as situações limites } \\
\text { identificadas no momento da construção coletiva do } \\
\text { currículo. }\end{array}$ \\
\hline $\begin{array}{l}\text { 8. Ausência do caderno de anotação em todas as } \\
\text { turmas em algumas alternâncias, gerando } \\
\text { dificuldade de diálogo entre docentes e } \\
\text { desintegração, o que prejudica o aprendizado } \\
\text { discente. }\end{array}$ & $\begin{array}{l}\text { Instrumento de anotações que facilitem as informações } \\
\text { acerca da mudança de condução das aulas conforme } \\
\text { acordado coletivamente. }\end{array}$ \\
\hline $\begin{array}{l}\text { 9. Ausência de alguns professores nas reuniões de } \\
\text { construção de Plano de pesquisa de cada Tempo } \\
\text { Comunidade. Isso tem gerado lacunas no PEPT. }\end{array}$ & $\begin{array}{l}\text { Participação de todos os professores que atuam na } \\
\text { alternância nas definições do plano de pesquisa em } \\
\text { cada Tempo comunidade }\end{array}$ \\
\hline $\begin{array}{l}\text { 10. Ausência de comprometimento pessoal e } \\
\text { profissional com a educação e com as populações } \\
\text { do campo por parte de alguns professores. } \\
\text { Isso tem gerado insatisfações no quadro docente } \\
\text { que participa e se dedica para assegurar uma } \\
\text { educação de qualidade. }\end{array}$ & $\begin{array}{l}\text { Participação de todos para apropriação Da proposta } \\
\text { pedagógica que tem como a realidade como objeto de } \\
\text { conhecimento e requer engajamento de todos para } \\
\text { assegurar a qualidade do ensino, sem lacunas. }\end{array}$ \\
\hline $\begin{array}{l}\text { 11. Ausência de compreensão sobre os modelos } \\
\text { pedagógicos, a concepção de formação humana, } \\
\text { integral e integrada, bem como da concepção de } \\
\text { educação do campo e Agroecologia, e da pesquisa, } \\
\text { trabalho e cultura como princípios educativos. }\end{array}$ & $\begin{array}{l}\text { Necessidade de elaboração de uma proposta de } \\
\text { formação continuada do CRMB, capaz de "afinar" } \\
\text { conceitos estruturantes entre os professores e técnicos } \\
\text { ligados ao ensino. }\end{array}$ \\
\hline
\end{tabular}

Fonte: Dados extraídos dos relatórios de formação continuada 2010-2016, sistematizados pela autora em 2016. 
O estudo dos relatórios de formação continuada de servidores realizada no período de 2011-2015, nos dois cursos técnicos em agropecuária e agroecologia integrados ao Ensino Médio, demonstrou que as lacunas passaram a se fazer presente a partir do final do ano de $2015^{11}$, e, em especial, após o fim da atuação da assessoria externa e a descontinuidade do processo de formação que assegurasse a compreensão dos pilares da proposta de educação do campo.

Essa problemática torna-se central com a rotatividade do quadro docente e de técnicos ligados ao ensino, seja pela remoção e ou pedido de demissão para atuar em outra instituição, seja pelo afastamento para estudo de cerca de 5\% dos professores e a ampliação do quadro docente em cerca de 50\% em 2016. O quadro em questão se agravou devido a ausência de uma política de formação continuada por parte do CRMB, somada a imposição do IFPA pelo cancelamento da especialização em Educação do Campo, Agroecologia e Questões pedagógicas que possuíam uma turma de 40 matriculados e com previsão de iniciar no segundo semestre de 2016.

Desse modo, o desconhecimento sobre a proposta pedagógica do campus que se estrutura pelos eixos: educação do campo, agroecologia e pedagogia da alternância; a concepção de ensino médio integrado; a concepção de formação profissional dos IFs; entre outros, gerou resistências e compreensões equivocadas sobre a proposta institucional do CRMB, a ponto dos professores reivindicarem a mudança do PPP, pautada na compreensão que é a instituição que tem que se adequar a visão dos novos servidores e não o contrário: os servidores se apropriarem da proposta institucional para colocá-la em prática.

As lacunas identificadas pelo estudo dos relatórios e pela observação participante perpassam pelas seguintes questões: incompreensão sobre a concepção de formação humana, interdisciplinar, integral e integrada; bem como no desconhecimento da pesquisa, do trabalho e da cultura como princípios formativos, devido a fragilidade na formação inicial dos docentes e técnicos ligados ao ensino. Além disso, há incompreensão sobre a relação ensino/pesquisa /extensão presente no percurso formativo dos cursos, presente na realização da alternância pedagógica. Esta incompreensão se limita a forma desenvolvida pelas Universidades brasileiras, as quais atuam apenas no ensino superior.

\footnotetext{
${ }^{11}$ A última formação continuada com presença da assessoria externa ocorreu na primeira semana de agosto de 2015, ficando pendente a retomada de elementos centrais sobre a elaboração e aplicação do plano de aula, cujas dificuldades foram identificadas durante a semana. A lacuna se deve a decisão da maioria dos professores em se retirar da formação para poder viajar para suas cidades de origem, tendo faltado no ultimo dia de estudo. Após isso a gestão não mais garantiu recursos de diárias e passagens para assegurar a presença da assessoria externa, o que levou a desconstrução processual das práticas interdisciplinares e integradas a partir de 2016.
} 
O desenvolvimento deste processo não foi apropriado por todos os professores do quadro docente a época, tão pouco assumido pela gestão eleita em 2016. Neste sentido, houve mudanças no PPP, retirando a perspectiva da formação via tema gerador e voltando para o currículo estruturado por eixo temático.

\section{CONSIDERAÇÕES FINAIS}

O resultado da pesquisa aponta a necessidade da retomada da política de formação continuada de servidores do CRMB, com momentos de estudo para o alinhamento conceitual, de modo a possibilitar que os novos servidores compreendam e atuem a favor da proposta pedagógica do referido campus.

Uma vez que é fundamental a retomada da atuação interdisciplinar em cada área e a integração entre áreas, o que requer a qualificação dos espaços de planejamento coletivo por área, seguida da socialização entre áreas, bem como de uma lotação que respeite as deliberações coletivas de cada área e das indicações do desenvolvimento de práticas docentes conjuntas em sala de aula e de atividades integradoras envolvendo os componentes de cada área, no decorrer de cada semestre.

Para isso, é fundamental que as coordenações de cursos assegurem na lotação a entrada de professores por área e em dias próximo em cada alternância e com cargas horárias que considere o processo de construção do conhecimento proposto no planejamento coletivo.

Somente esse processo poderá evitar a fragmentação do conhecimento e oportunizar a articulação entre teoria e práticas entre ensino, pesquisa e extensão presentes na relação entre os tempos/escola e os tempos/comunidade.

Essa realidade requer a capacidade da gestão do ensino em promover espaços de reflexão em três diferentes momentos: na ação, que aconteceu no momento em que os docentes planejam e realizam as atividades e refletem sobre o sentido e o significado da educação; sobre a ação, desenvolvida nos tempos-escola no decorrer do período de internato, por meio da troca de saberes adquiridos e construídos no cotidiano da comunidade e da sala de aula; sobre a reflexão na ação, momentos em que eles retornam à prática refletida, que se dá após a reflexão coletiva acerca das ações realizadas anteriormente, possibilitando mudança nas práticas, visto que na socialização dá-se a reflexão sobre as ações desenvolvidas nos tempos escola e comunidade, quando eles também aprendem com a experiência do outro. $\mathrm{O}$ que os leva ao exercício de novas formas de atuarem em sala de aula. 
Além disso, requer análise qualitativa sobre os saberes fundamentais à prática docente não limitada a teorização, mas em favor da necessária eticidade da prática educativa (FREIRE, 1996).

$\mathrm{Na}$ vivência desse processo de construção coletiva do currículo, o principal desafio esteve em desenvolver um processo formativo capaz de "afinar" princípios e conceitos assumidos pelo CRMB, "nivelar" a compreensão acerca dos pressupostos e princípios teóricometodológicos que orientam a implementação da política pública educacional da instituição, bem como, compreender a concepção de educação, de pesquisa, de extensão, de desenvolvimento, de currículo, entre outras, assumida pelo CRMB, na perspectiva de ajudar a consolidar a matriz técnico-científica calcada nos princípios agroecológicos, além da indissociabilidade da relação tempos/escola, tempos/comunidade e tempos/escola/retorno, pois ela representa uma busca constante de não cair no desvio de entender o tempo/comunidade como o tempo de prática e o tempo/escola como o tempo de teoria, devido a descontinuidade do quadro de servidores.

\section{REFERENCIAS}

ARCAFAR/PA. Ata de fundação, Belém, 2003.

MENDES, I. A. Didática. Natal, RN: EDUFRN - Editora da UFRN, 2006.

BRASIL/MEC. Lei de Diretrizes e Bases da Educação Nacional, n 9.394 , de 20 de dezembro de 1996.

. Diretrizes Operacionais para a Educação Básica nas Escolas do Campo. $\overline{\text { Resolução CNE/CEB N }}$ 1, de 3 de Abril de 2002.

CALAZANS, M. J. C.Questões e contradições da educação rural no Brasil. In: Educação Rural n Brasil, Paz e terra, 1981.

CORTELLA, M. S. A escola e o conhecimento: fundamentos epistemológicos e políticos. 11. ed. São Paulo: Cortez: Instituto Paulo Freire, 2008.

DI PIERRO, M. C. Descentralização, focalização e parceria: uma análise nas tendências das políticas de educação de jovens e adultos. Revista Educação e Pesquisa, São Paulo. vol. 7, n 2, 2001.

IFPA. Projeto Político-Pedagógico do Campus Rural de Marabá, 2010.

CRMB/IFPA. Relatórios Anuais da Formação Continuada do CRMB, 2011, 2012, 2013, 2104, 2015. 
FERNANDES, B. M. e MOLINA, M. C. o Campo da Educação do Campo. In: contribuições para a construção de um projeto de campo. Brasília, DF, 2004.

FREIRE, P. Criando métodos de pesquisa alternativa: aprendendo a fazê-la melhor através da ação. In: Brandão, C. R. Pesquisa Participante. São Paulo, brasiliense, 1981.

Pedagogia do Oprimido. 17ºed, Rio de Janeiro: Paz e Terra, 1987.

Pedagogia da autonomia: saberes necessários à prática educativa. São Paulo: Paz e Terra, 1996.

MOLINA, M. C. Contribuições para Construção de um Projeto de Educação do campo. In: ARROY, M. G. Por Um trato Público da Educação do Campo. Brasília DF: Articulação Nacional Por Uma Educação do Campo, 2004.

- A Contribuição do PRONERA na Construção de Políticas Públicas de Educação do Campo e Desenvolvimento Sustentável. Tese (doutorado em Desenvolvimento), Pós-Graduação da USP, São Paulo, em 2003.

MICLELOTTI, F. Educação do Campo: reflexões a partir da tríade ProduçãoCidadania-Pesquisa. In: SANTOS, Clarice Aparecida (Org.). Por uma Educação do Campo: Campo-Políticas Públicas- educação. Brasília: Incra; MDA, 2007.

PERnAmbuCO, M. M. A. C \& PAIVA, I. Metodologia e Conteúdo. Caderno Educação e Realidade ${ }^{\circ} 15$. UNIDIS/UFRN, 2006.

RAMOS, M. N. Possibilidades e Desafios na Organização do Currículo Integrado: In: RAMOS, M. N; et all. Ensino Médio Integrado: Concepção e Contradições. São Paulo: Cortez, 2005.

RAMOS, M. N. et al (Coords). Referências para uma política nacional de educação do campo: caderno de subsídios. Brasília: Secretaria de Educação Média e Tecnológica. Grupo Permanente de Trabalho de Educação do Campo, 2004.

REIS, N. Educação e Sociedade: História de Professores da Transamazônica (Tese Programa de Pós-Graduação em Educação da Universidade federal do Rio Grande do Norte), 2006.

SANTOMÉ, J. Globalização e Interdisciplinaridade: O Currículo Integrado. Porto Alegre: Artes Médicas, 1998.

SEVERINO, A. J.. O compromisso dos educadores com o interdisciplinar: a exigência da teoria e da prática In: Interdisciplinaridade: para além da filosofia do sujeito. Vozes, 1995.

SCALABRIN, R. Diálogos e Aprendizagens na formação em agronomia para assentados. (Tese - Programa de Pós-Graduação em Educação da Universidade federal do Rio Grande do Norte), 2011.

SOARES, E. de A. L. Parecer $\mathbf{N}^{\mathbf{3}}$ 36/2001 sobre as Diretrizes Operacionais para a Educação Básica das Escolas do Campo. Brasília, DF: 2001. 
TREVIZAN, S. O que é o rural? O que é o Urbano? O que é a Educação? mimeo, 2000.

VIA CAMPESINA. Educação do Campo: direito de todos os camponeses e camponesas. Brasil: 2006.

Recebido em 22.02.2019

Aprovado em 07.04.2019 